Perspective

\title{
Apoptosis in Living Animals Is Assisted by Scavenger Cells and Thus May Not Mainly Go through the Cyto- chrome C-Caspase Pathway
}

\author{
Bingya Liu ${ }^{\circledR}$, Ningzhi Xu ${ }^{2}$, Yangao Man ${ }^{\circledR}$, Haihong Shen ${ }^{4}$, Itzhak Avital ${ }^{3}$, Alexander Stojadinovic ${ }^{3}$, and \\ D. Joshua Liao $^{5}$ \\ 1. Shanghai Key Laboratory of Gastric Neoplasms, Ruijin Hospital, Shanghai Jiao Tong University School of Medicine, Shanghai 200025, \\ P. R. China. \\ 2. Laboratory of Cell and Molecular Biology, Cancer Institute, Academy of Medical Science, Beijing 100021, P.R. China. \\ 3. Bon Secours Cancer Institute, Richmond, VA 23230, USA. \\ 4. School of life Sciences, Gwangju Institute of Science and Technology, Gwangju 500-712, Korea. \\ 5. Hormel Institute, University of Minnesota, Austin, MN 55912, USA.
}

$\triangle$ Corresponding authors: Bingya Liu, Shanghai Key Laboratory of Gastric Neoplasms, Ruijin Hospital, Shanghai Jiao Tong University School of Medicine, Shanghai 200025, P. R. China. Tel: 86-21-64670644 Email: byliu@sjtu.edu.cn or Ningzhi Xu, Laboratory of Cell and Molecular Biology, Cancer Institute, Academy of Medical Science, Beijing 100021, P.R. China. Tel: 86-10-87788487 Email: xningzhi@public.bta.net.cn or Yangao Man, Bon Secours Cancer Institute, Richmond, VA 23230, USA. Tel: 1-301-879-0816 Email: yanmann@aol.com or D. Joshua Liao, Hormel Institute, Austin MN 55912, USA. Tel: 1-507-437-9665 Email: djliao@hi.umn.edu.

(C) Ivyspring International Publisher. This is an open-access article distributed under the terms of the Creative Commons License (http://creativecommons.org/ licenses/by-nc-nd/3.0/). Reproduction is permitted for personal, noncommercial use, provided that the article is in whole, unmodified, and properly cited.

Received: 2013.09.03; Accepted: 2013.10.19; Published: 2013.11.15

\begin{abstract}
Because billions of cells die every day in their bodies, animals have evolutionarily developed apoptosis to preserve the tissue environment from adverse effects of dead cells, a process achieved via phagocytosis of the cell corpses by professional or amateur phagocytes that are collectively referred to as scavengers. Hence, apoptosis is a merger of two procedures separately occurring inside the dying and the scavenger cells, respectively. The task of apoptosis research is to study how these death procedures occur without hurting the host tissues, and recruitment of in vitro system into the study must be justified for this purpose. Cells in culture have no motivation to preserve the environment, and their death does not involve corpse clearance by scavengers. Therefore, programmed cell death in culture should be redefined, for example as stress-induced cell death, to avoid many sources of confusions, since the word "apoptosis" had already been defined, prior to the era of cell culture, as a silent and beneficial cell suicide with corpse clearance as a distinctive hallmark. We should start over again on apoptosis research by determining whether different physiological apoptotic procedures in animals involve the cytochrome c-caspase pathway, since it has been established from cultured cells as a central mechanism of "apoptosis" but whether it overarches any physiological apoptotic procedure in animals is still unclear. Probably, cells in living animals are programmed to use scavengers to assist their apoptosis but cells in culture have no scavengers to help and thus need to go mainly through the cytochrome c-caspase pathway.
\end{abstract}

Key words: apoptosis, scavengers, c-caspase pathway

\section{Introduction}

One million cells die every second in the human body, according to some estimation (1-4), or 60 billion cells every day according to another estimation (5). Brown and Neher recently summarized the cellular 
death toll of major organs and tissues (6). Many dead cells will shed from the skin or will shed into a lumen and then be excreted out of the body as a component of feces, urine, milk, phlegm, saliva, etc. These dead cells are thus not a concern herein. However, most of our cells do not reside in close vicinity to the body surface or a lumen; their death would leave the host tissue or organ with cell corpses, ensuing decomposed cellular debris and various toxic and immunogenic components, which then stimulate inflammation and may cause autoimmune diseases and many other adverse effects (7). Therefore, to preserve the tissue environment, animals have evolved programmed cell death mechanisms (8), herein collectively referred to as apoptosis for simplicity, that do not leave the host tissue with cellular dregs $(9,10)$. Simply put, a swift but silent clearance of no-longer-useful cells probably is all that apoptosis is about, which is the reason why dead cells, although huge in number, are rarely discerned in normal tissues (11).

Apoptosis is generally considered as a suicidal event, although sometimes the suicide is not intentional but rather is due to some reason or is ordered by "someone" (7), as exemplified by various in vivo cell competitions in which the cells that proliferate more quickly "force" their neighboring cells that proliferate relatively slowly to die of apoptosis (12-14). Apoptosis of immature thymocytes induced by glucocorticoid hormones may be another example (15). Therefore, the dying or dead cells are herein referred to as "suicidal cells" for simplicity. The swift clearance of the suicidal cells, such as those cells that die simply because they cannot proliferate as quickly as the others (14), is carried out via phagocytosis by professional or amateur phagocytes that are collectively referred to as "scavenger cells" $(7,14)$. Besides macrophages, some tumor cells $(16,17)$ and some normal epithelial cells can also engulf suicidal cells, such as some alveolar epithelial cells in the mammary gland (18) and some bronchial epithelial cells in the lung (19). In chemical-induced hyperplastic liver and kidney, many apoptotic hepatocytes or renal cells are probably phagocytosed by their fellow hepatocytes or renal epithelial cells as well (20-23). However, these amateur phagocytes mainly devour their neighboring cells, whereas macrophages often migrate a long distance and can gulp down many prey cells, as seen in c-Myc-induced mouse mammary tumors (Fig. 1) (24). Although there have been many different definitions or descriptions of cell death, with some conflicting with the others $(10,25,26)$, whether or not the death involves scavengers disposing of the cell corpses that are not shed always clearly distinguishes apoptosis from non-apoptosis. Unfortunately, in many studies cells are pronounced apoptotic without evidence of corpse clearance provided, wherein the cells may not really die of apoptosis as claimed. Since apoptosis starts with the motivation for tissue preservation and ends at the cell corpse clearance, any demise that does not begin and end in this way should not be called apoptosis, in our opinion.
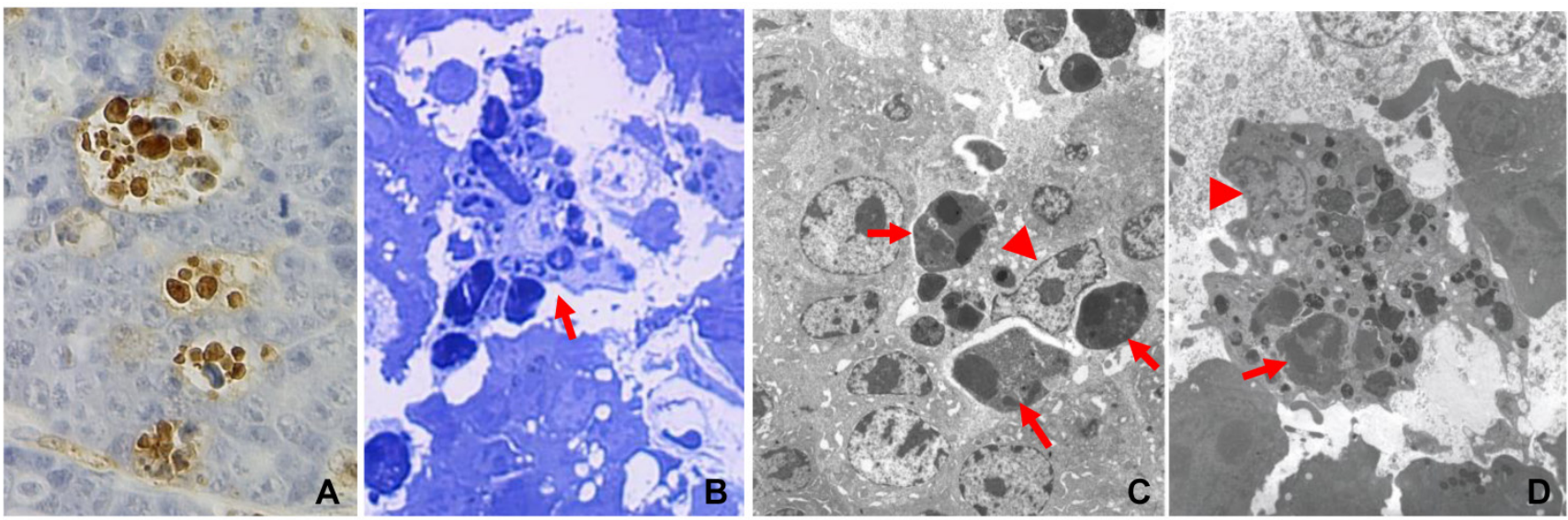

Fig I. Engulfment of apoptotic cells by macrophages in c-myc induced mouse mammary tumors, with details in reference (7). A: TUNEL-staining of a paraffin-section of a mammary tumor from an MMTV-c-myc transgenic mouse shows that multiple positive (brown color) nuclei are clustered together, because one macrophage has engulfed multiple apoptotic cells. B: Toluidine blue staining of a semi-thin section of a resin-embedded tumor tissue shows, under a light microscope, multiple apoptotic cells as phagosomes inside a macrophage (arrow). C \& D: Electron microscopic photos show macrophages that contain many phagosomes (arrows). Arrowhead indicates the nucleus of the macrophage. 


\section{In vivo, suicidal cells communicate with scavengers}

Apoptotic cells are dispersed throughout many the healthy live cells within the organs or tissues. At which stage of the suicidal procedure a cell is engulfed by a scavenger varies among different situations, but it often occurs when the cell is dying but still alive, or "undead" as put in the literature (27). Even healthy cells may be engulfed by phagocytes if they are redundant or no-longer-useful (6), which in our view is more like euthanasia than homicide. When a cell has decided to commit suicide, or has been ordered to do so, it sends out "find-me" signals for a scavenger to find it and presents "eat-me" signals on its cell surface as a permission for a scavenger to gobble it up $(1,6,28)$. Although these signals are still largely uncharacterized and the signal molecules identified hitherto still cannot explain many of our questions, it is clear that scavengers may come from a long distance in some situations, indicating that some "find-me" signals can go long distances and probably even recruit a mediator in a systematic or endocrine manner $(11,29)$. Obviously, the long-distance travel of "find-me" signals and scavengers becomes possible only in those organisms with blood and lymphatic vessels, including capillaries, but not in some low-level organisms such as C. elegans. On the other hand, the appearance of the blood-testis, blood-brain and blood-thymus barriers and probably even the placenta may create organ-specific apoptotic mechanisms in higher animals. These are worth noting because so far studies on the species- and organ-specificities of apoptosis have seldom addressed the aspect of cell corpse disposal.

To receive suicidal cells' signals, scavenger cells present receptor molecules on their surface. However, sometimes the receptor cannot directly recognize "eat-me" signals; in this situation suicidal cells also need to express and secrete additional, so-called "bridging", molecules to join the "eat-me" signals with the scavenger's surface receptors (Fig. 2). In the meantime, many surrounding healthy cells need to express "don't-eat-me" signals to avoid being mistakenly devoured by a scavenger, whereas the expression of "don't-eat-me" molecules is decreased in suicidal cells to further facilitate their engulfment by a scavenger (28). Since many "find-me", "eat-me", "bridging" and "don't-eat-me" molecules as well as macrophages' receptors have been identified and comprehensively reviewed recently $(1,6,9,28)$, we just list several of them that can be detected by an immunohistochemical approach in animal tissues as closely relevant to our topic (table 1).
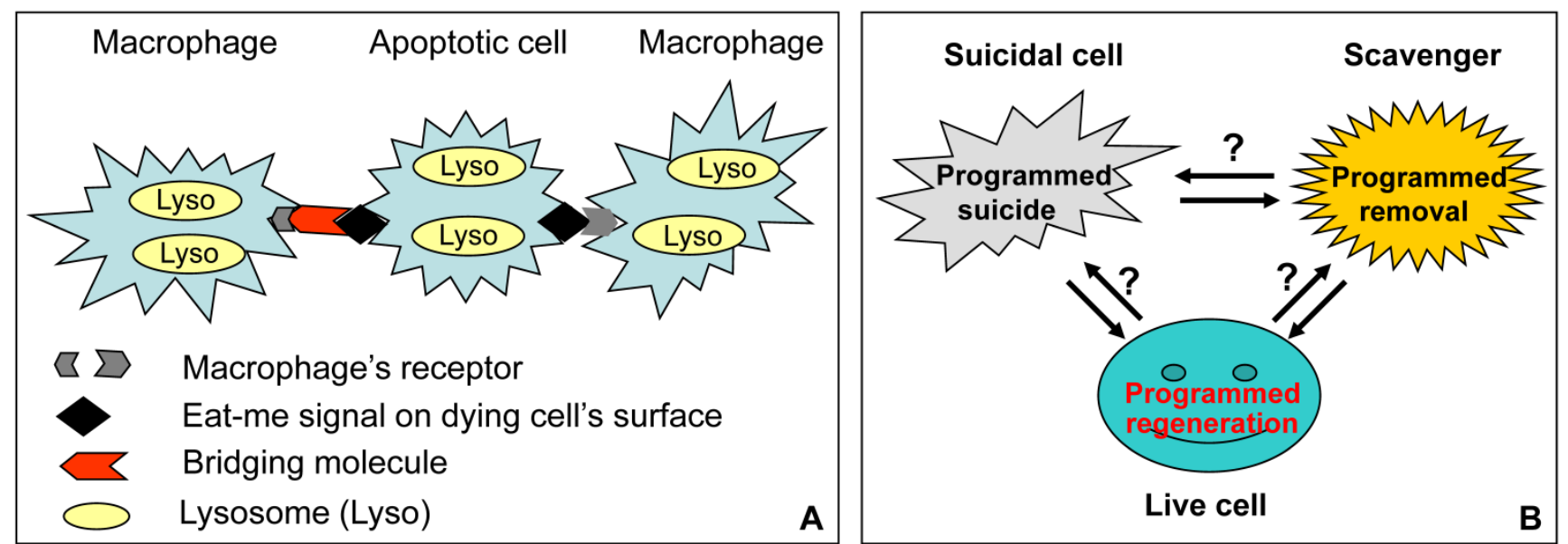

Fig 2. Relationships among suicidal cell, scavenger cell and live cell in a tissue of living animal. A: As best studied with macrophages, a scavenger's surface receptor directly recognizes an "eat-me" molecule on the surface of an apoptotic cell, or uses a "bridging" molecule to tether the "eat-me" molecule. After engulfment, the macrophage's lysosomal enzymes continue the killing procedure if the cell is still alive (in this case apoptosis is actually a combination of suicide and euthanasia), and then decompose the corpse. Although in vitro studies suggest that lysosomal enzymes may elicit caspase-independent apoptosis, in living animals how these enzymes act before and after the cell is engulfed, and whether or not they coordinate with scavenger's enzymes, have not yet been fully characterized. B: Apoptosis in living animals is a game involving three players, i.e. the suicidal cell, the scavenger and many surrounding live cells. Each of the three not only executes a highly programmed series of actions, i.e. suicide, corpse removal and cell regeneration, respectively, but also coordinates with the other two players to maintain the tissue homoeostasis. In contrast, cell death in a Petri dish is one-player game, i.e. it is the suicidal cell's own business, because the cell has no need to discuss with the live cells about the regeneration issue, and with scavengers about the corpse it will leave behind. (Oppositely oriented double-arrows indicate mutual communications between the two players, whereas question marks indicate the current lack of strong evidence.) 
Table I. Signal molecules that mediate phagocytosis.

\begin{tabular}{|l|l|}
\hline \multirow{4}{*}{ Eat-me } & Annexin A1 \\
\cline { 2 - 2 } & Cell surface calreticulin (CRT) \\
\cline { 2 - 2 } & Phosphatidylserine (PS) \\
\cline { 2 - 2 } & Annexin V (marker for PS on cell surface) \\
\hline \multirow{3}{*}{ Bridging } & Galectin-3 \\
\cline { 2 - 2 } & Milk fat globule EGF-like factor-8 (MFG-E8) \\
\cline { 2 - 2 } & Growth arrest-specific 6 (Gas-6) \\
\cline { 2 - 2 } & Plasminogen activator inhibitor-1 (PAI-1) \\
\cline { 2 - 2 } $\begin{array}{l}\text { Macrophage's } \\
\text { receptor }\end{array}$ & CD200 \\
\cline { 2 - 2 } & CD31 \\
\cline { 2 - 2 } & Vitronectin receptor \\
\cline { 2 - 2 } & CD91 \\
\hline
\end{tabular}

Note: Only some of many molecules that mediate phagocytosis are listed. These molecules can be detected by not only immunocytochemistry on cultured cells but also immunohistochemistry on paraffin-embedded tissue sections.

While the suicidal cell signals the scavengers, the scavengers themselves may also send out "got it" confirmation. However, although macrophages are known to secrete many molecules that influence apoptosis of other cells $(15,30,31)$, the specific messages from a scavenger to its to-be-engulfed cell are poorly studied. Nevertheless, there are indications, such as that macrophages, upon uptake of apoptotic thymocytes, produce TGF $\beta$ and retinoids, which in turn induce expression of transglutaminase-2, an apoptosis-regulating protein, in other thymocytes $(15,32)$. Also, it has been shown that apoptotic cells in an animal tissue actively migrate towards macrophages (33), and this process is probably guided by signals from the macrophages themselves. Possibly, some soluble molecules secreted by scavengers serve as signals that direct the suicidal cell to prepare itself for engulfment. When the scavenger is a neighboring fellow epithelial cell or fellow cancer cell, such as in the mammary gland (18), the lung (19), the liver (20-22), or some cancer tissues (17), it may signal its prey more easily. Nevertheless, whether and how in living animals scavengers instruct their prey to cooperate are still largely unknown and remain to be determined by future research (Fig. 2B).

\section{Cells are often pronounced as apoptotic without evidence of corpse disposal pro- vided}

Cell death is a persistent event in any cell culture system, as there always are some dead cells present. The cell corpse decomposes to debris, somewhat resembling a secondary necrosis but without the presence of neutrophil granulocytes and other inflammatory cells. In such an environment with decomposed corpses, live cells' health and growth rate are likely to be affected. The death of some cells may drive prolif- eration of the remaining live cells during the early phase of culture, but with increased cellular dregs, the overall growth rate is inhibited $(11,29)$. A related issue pertains to the use of death-inducing agents. For example, almost all in vitro studies evaluating the efficacy of anticancer drugs use apoptosis as a readout without realizing that the changes in the apoptotic markers used reflect only the lysis and decomposition of the dead cells, whereas the drug does not really kill by eliciting apoptosis (34). Drugs can alter the expression and activation of apoptosis-regulatory proteins, in part because all these proteins also have non-apoptotic functions, even in animals (35-37). Regardless of how a drug kills, the drug increases the death toll and the ensuing cellular dregs, taking the culture system further away from the real situation in animals wherein, thanks to the scavengers, dead cells are rarely discerned (11). In vivo efficacy of an anticancer drug is usually tested using xenograft tumor models with athymic mice. However, ironically, the drug often causes tumor necrosis, and the expression of "eat-me", "don't-eat-me" and "bridging" molecules as well as macrophage surface receptors in the xenograft tumors is rarely determined to show the corpse clearance as an in vivo evidence for the true apoptotic effect of the drug. There are many constraints for study of corpse disposal in a tissue. For example, many "find-me" molecules such as ATP, UTP and other nucleotides are soluble $(1,6,28)$ and thus difficult to detect with histology-related methods. However, some engulfment-related molecules can still be detected by immunohistochemistry on paraffin-embedded tissues (table 1).

\section{In vivo, apoptosis is also under the con- trol of the surrounding live cells}

With a huge number of cells lost to apoptosis every day, our body needs to regenerate the same number of cells to maintain tissue homoeostasis. This death-triggered regeneration or compensatory proliferation is a highly programmed event and involves dialog between the suicidal and live cells (Fig. 2) (27), as suggested by the fact that the number of apoptotic cells in embryos can be fine-tuned to meet a developmental need. For instance, during digit individualization at the embryonic stage, the number of apoptotic cells in the hands is adjusted until the fingers are formed perfectly, otherwise they would be like ducks' webbed limbs $(9,38)$. Maturation of the nervous system, which involves massive cell death, may be another example $(9,39)$. Moreover, in various c-myc transgenic animals, the cells that express a higher c-myc level are known to force those neighboring cells expressing a lower c-myc level to die of apoptosis, as reviewed previously (40). In this and in many other 
types of cell competition (14), there likely are some instructions from the higher c-myc or the quickly-proliferating cells to the suicidal cells. Unfortunately, thus far few studies have focused on, especially, the instructions from the surrounding live cells to the suicidal cells during apoptotic procedure. It is worth noting that such cell communications may not occur in Petri dishes wherein the suicidal cells have no interest in whether or not the cell loss will later be compensated.

\section{Apoptosis consists of two lines of proce- dure, one in the dying cell and the other in the scavenger}

What we often forget is not only why animals equip themselves with apoptotic mechanisms but also that apoptosis in animals consists of two separate but parallel lines of procedure. One line occurs within the suicidal cell, which is commonly considered to involve release of cytochrome $\mathrm{c}$ from the mitochondrial outer membrane and cleavage of different caspases, although we suspect that these proteins may be used more often in stress-induced demise (7) whereas physiological apoptosis may employ different, such as lysosomal (41), sets of proteins. The other line of procedure occurs outside the suicidal cell (before it is engulfed) but inside the scavenger, which starts long before engulfment, involves enzymes of the scavenger, and ends at complete decomposition and assimilation of the prey as a sort of cannibalism in order to recycle nutrients. In cancers the situation is more complex, because engulfment of a cancer cell by another renders the predator itself more malignant (17). Cell removal by scavengers is a highly programmed event as well (42). While each of these two lines has been studied relatively well, the merger of the two, after the engulfment, is understudied in part because it can mainly be explored in animals. Co-culture of suicidal cells with macrophages has been used to overcome some limitations of the culture systems. However, many questions about its resemblance to in vivo situations remain unanswered, such as whether cells in a Petri dish are still highly motivated to use an apoptotic mechanism to keep the environment clean; otherwise they just simply use any convenient way to commit suicide, leaving us to wonder why there are so many "mechanisms" and "pathways". Police regard motivation seriously when investigating a crime, so should we when detecting apoptotic mechanisms. To what extent the direct contact between the predator and its prey in a dish resembles their communications in living animals is among the most important unanswered questions.

\section{We might in the past have taken the un- usual as the usual but now take the usual as the unusual}

The negotiation between the suicidal cell and the scavenger, as well as the merger of the two cellular processes described above, are the key issues that perplex us greatly and motivated us to write this perspective as a new version of a previous one (7), since most apoptotic pathways are established on cell culture studies and often sans strong support from animal models $(43,44)$. We imagine that in cell culture, a suicidal cell may still, at the very beginning, try to contact scavengers to assist its suicide and prearrange its body disposal, as seen in living animals, hoping to use their feedback to plan or amend its suicidal procedures. However, it never receives such feedback because there is no scavenger around. Under this unusual situation, the cell has to execute an unusual succession of suicidal procedures, otherwise unnecessary, to minimize the adverse effects of its corpse. Restated, cell death in a Petri dish may still be a programmed event, but programmed differently because no scavengers around to assist the death and the body disposal. Many apoptotic pathways established from in vitro studies may be such alternatives or backups that are not used in normal situations, i.e. in living animals. In other words, while SOP (Standard Operation Procedure) is what we need, cells in a dish might have given us EOP (Emergency Operation Procedure) instead, in which cleavage of caspases is a major step. Probably, we might in the past have mistakenly taken the unusual as the usual and now take the usual as the unusual, which may be why there are many unexpected results from animal models with apoptosis-regulatory genes knocked out and why there are too many exceptions to established pathways $(7,39,43-45)$. An analogy is that some of us leave the building from an emergency exit for convenience on a daily basis without realizing that it should only be used for emergencies. As an example, one of us previously considered that c-Myc-induced apoptosis in mouse mammary tumors was not a typical one as it differed greatly from the canonical pathways $(24,46)$, but we now consider that it is actually a paradigm of apoptosis in vivo (Fig. 1). Involution of post-weaning mammary glands, the only other example of genuine apoptosis that has been characterized so far, is a procedure of massive cell death that is, unexpectedly, independent of caspases, "which calls for reassessment of other cell death events in which caspases might be activated not as a cause, but as a consequence, of PCD" (41). 


\section{Ironically, genuine apoptosis has been understudied}

Besides the aforementioned involution of post-weaning mammary glands, there are many other physiological models of apoptosis. Examples include embryonic development of many tissues or organs (9,37-39), postpartum involution of the uterus (47-49), spermatogenesis in the testis $(50,51)$, ovum maturation in the ovary (52-54), post-pubertal involution of the thymus $(55,56)$, and involution of vaginal, uterine and prostate epithelium during aging (57-62). Unfortunately, many peers often forget that exploration of how these (and many other) canonical apoptotic procedures occur without hurting the host tissue is the primary task and ultimate goal of apoptosis research, and any recruitment of in vitro systems into the study to overcome in vivo constraints must be justified for this task or goal. The cytochrome c-caspase pathway has been established, owing to huge efforts put, as a central mechanism of "apoptosis", but there actually is a dearth of convincing evidence proving that this pathway overarches any of these physiological apoptotic procedures. For instance, post-weaning involution of mammary glands occurs normally in caspase-3 knockout mice (41). Although lack of evidence should not be taken as evidence of lack, it is one of the possibilities, meaning that these models may not use this pathway. In this regard, it is a sad fact that true apoptosis has been greatly understudied, largely because much effort has been shifted from the above-mentioned primary task to stress-induced cell death, which is not apoptosis but is another important research area meaningful for many biomedical aspects, such as cancer therapy.

Probably, in animals, some enzymes of the suicidal cells that are not categorized in cell culture studies as canonical players in apoptosis may initially play major roles, and then some scavenger's enzymes take over to complete the entire apoptotic event. The more downstream along an apoptotic pathway, the deeper the scavenger's components such as lysosomal enzymes (41) are involved, thus with a greater difference from what has been established by in vitro studies. Now is the time to merge the two processes separately occurring in the suicidal and scavenger cells into one authentic pathway of apoptosis.

\section{A lot needs to be done, but what is the imperative?}

We all know that studies in vitro differ greatly from those in vivo, but what the above sections described obviously goes far beyond the general differences, as it points out that many in vitro studies are not justified for, or cannot serve, the primary purpose of apoptosis research defined above. Moreover, normal cells in animals are programmed to die eventually, whereas in a Petri dish cell lines have been reprogrammed to be immortal. In vitro studies then, basically, decipher the death program only in reprogrammed cell lines. Thus, after all these years and much effort, we need to return to square one and start over again on apoptosis research, which is to decode the original death program, but not the reprogrammed version. The most imperative task is to determine whether the cytochrome c-caspase pathway is also the central mechanism in any of the above-mentioned physiological animal models, since this mechanism is established mainly from cell culture and is the main source of the confusions on apoptosis research. The in vivo situation is often complicated by the fact that the engulfed cell is still alive and is then actually killed by the scavenger $(6,27)$, making apoptosis often a combination of suicide and euthanasia (as we are reluctant to consider the scavenger as a guilty murderer). If, as we have suspected (7), these physiological apoptotic procedures in higher animals do not go through the cytochrome c-caspase pathway, just like the post-weaning involution of mammary glands (41), fundamental work is needed to build the skeleton of in vivo apoptosis, so that we can later disassemble the results from Petri dishes into small pieces and put them onto this scaffold to construct in vivo models of apoptosis. This is another way of admitting that the previously obtained in vitro data are still very useful. Considering that the cytochrome c-caspase pathway has been firmly established but apoptosis is a phenomenon seen in animals for a much longer time as reviewed previously (7), we propose to redefine the cell death that uses this pathway, for example as stress-induced cell death, to be distinguishable from authentic apoptosis. An analogy to explain the need for such redefinition is that animals had, long before the era of cell culture, "patented" apoptosis as a swift but beneficial cell suicide with corpse clearance as a distinctive hallmark, although there was no word "apoptosis" until 1972, and thus cell culture systems should not use it. Redefining programmed cell death in the Petri dish should help peers to discern the demarcation between these two types of cell death, since one seems to rely on the scavengers while the other seems to recruit the cytochrome c-caspase system because of no scavengers to rely on. The peers who have interest in apoptosis should start from different physiological animal models. Various knockout or transgenic animals can be used but those data that do not dovetail the cytochrome c-caspase pathway should be more carefully explained. Besides these imperative tasks, many understudied areas mentioned in different sections of 
this primer should be explored in the future as well.

\section{Conclusion}

The primary task of apoptosis research is to study various programmed suicidal procedures of cells in animals that preserve the host tissues, and any employment of in vitro system into the study must be justified for this purpose. What is often neglected is that cell death in vitro has no concern for the "environmental pollution", does not engage scavengers, thereby resulting in accumulation of cellular debris, and is not regulated by the surrounding live cells. In other words, cell culture systems not only dismiss systematic regulation but also lay off two key players, i.e. the scavenger and the live cell, leaving the death procedure a one-player game with ample trash around, in contrast to apoptosis in animals, which is a three-player game leaving a neat stadium behind (Fig. 2). In a nutshell, apoptosis is a merger of two or even three separate, programmed events, i.e. cell suicide, corpse removal and even cell regeneration (Fig. 2), but demise in culture has no such merger. Because apoptosis was defined, before the spread of cell culture technology, as a silent and beneficial cell suicide with corpse disposal as a distinctive hallmark (7), we should leave the concept of "apoptosis" to animals and redefine the death of cultured cells. Redefining the concepts is of importance as it would help delineate many confused concepts and subroutines of apoptosis $(10,25)$ and help bring peers back to the studies of true apoptosis in, especially, those aforementioned physiological animal models. Future studies should determine whether apoptosis in animals uses the cytochrome c-caspase pathway since we suspect that it is only used by cell lines in culture, not only because the death program of cell lines have been reprogrammed but also because cells in living animals have scavengers to do much of the job. We probably have made a simple situation complex by mixing up the two systems. A caveat, which may comfort some readers, is that cell culture can still be used to dissect some steps of apoptosis as long as the issues narrated herein, especially the primary task and ultimate goal of apoptosis research, are kept in mind when designing experiments.

\section{Acknowledgements}

We think Dr. QingHua Shi at the Department of Life Sciences, University of Science and Technology of China at Hefei City, for his valuable comments. We also thank Dr. Fred Bogott in Austin Medical Center, Austin of Minnesota, as well as Drs. Margot Cleary, Michael Grossmann and Edward Hinchcliffe in Hormel Institute, University of Minnesota for their English editing of the manuscript. D.J. Liao was sup- ported by a grant from the Department of Defense of the United States (DOD Award W81XWH-11-1-0119).

\section{Competing Interests}

The authors have declared that no competing interest exists.

\section{References}

1. Ravichandran KS. Beginnings of a good apoptotic meal: the find-me and eat-me signaling pathways. Immunity 2011;35:445-55.

2. Henson PM. Dampening inflammation. Nat Immunol 2005;6:1179-81.

3. Nagata S, Hanayama R, Kawane K. Autoimmunity and the clearance of dead cells. Cell 2010;140:619-30.

4. Han CZ, Ravichandran KS. Metabolic connections during apoptotic cell engulfment. Cell 2011;147:1442-5.

5. Cotter TG. Apoptosis and cancer: the genesis of a research field. Nat Rev Cancer 2009;9:501-7.

6. Brown GC, Neher JJ. Eaten alive! Cell death by primary phagocytosis: 'phagoptosis'. Trends Biochem Sci 2012;37:325-32.

7. Liao DJ. The scavenger cell hypothesis of apoptosis: apoptosis redefined as a process by which a cell in living tissue is destroyed by phagocytosis. Med Hypotheses 2005;65:23-8.

8. Zmasek CM, Godzik A. Evolution of the animal apoptosis network. Cold Spring Harb Perspect Biol 2013;5:a008649.

9. Fuchs Y, Steller H. Programmed cell death in animal development and disease. Cell 2011;147:742-58.

10. Yuan J, Kroemer G. Alternative cell death mechanisms in development and beyond. Genes Dev 2010;24:2592-602.

11. Gregory CD, Pound JD. Cell death in the neighbourhood: direct microenvironmental effects of apoptosis in normal and neoplastic tissues. J Pathol 2011;223:177-94.

12. Vivarelli S, Wagstaff L, Piddini E. Cell wars: regulation of cell survival and proliferation by cell competition. Essays Biochem 2012;53:69-82.

13. Levayer R, Moreno E. Mechanisms of cell competition: themes and variations. J Cell Biol 2013;200:689-98.

14. Lolo FN, Tinto SC, Moreno E. How winner cells cause the demise of loser cells: cell competition causes apoptosis of suboptimal cells: their dregs are removed by hemocytes, thus preserving tissue homeostasis. Bioessays 2013:35:348-53.

15. Szondy Z, Garabuczi E, Toth K, Kiss B, Koroskenyi K. Thymocyte death by neglect: contribution of engulfing macrophages. Eur J Immunol 2012;42:1662-7.

16. Kerr JF, Wyllie AH, Currie AR. Apoptosis: a basic biological phenomenon with wide-ranging implications in tissue kinetics. Br J Cancer 1972;26:239-57.

17. Seyfried TN, Huysentruyt LC. On the origin of cancer metastasis. Crit Rev Oncog 2013;18:43-73.

18. Monks J, Smith-Steinhart C, Kruk ER, Fadok VA, Henson PM. Epithelial cells remove apoptotic epithelial cells during post-lactation involution of the mouse mammary gland. Biol Reprod 2008;78:586-94.

19. Juncadella IJ, Kadl A, Sharma AK et al. Apoptotic cell clearance by bronchial epithelial cells critically influences airway inflammation. Nature 2013;493:547-51.

20. Bursch W, Ellinger A, Gerner C, Frohwein U, Schulte-Hermann R. Programmed cell death (PCD). Apoptosis, autophagic PCD, or others? Ann N Y Acad Sci 2000;926:1-12.

21. Columbano A, Ledda-Columbano GM, Coni PP et al. Occurrence of cell death (apoptosis) during the involution of liver hyperplasia. Lab Invest 1985;52:670-5.

22. Columbano A, Ledda-Columbano GM, Rao PM, Rajalakshmi S, Sarma DS. Occurrence of cell death (apoptosis) in preneoplastic and neoplastic liver cells. A sequential study. Am J Pathol 1984;116:441-6.

23. Ledda-Columbano GM, Columbano A, Coni P, Faa G, Pani P. Cell deletion by apoptosis during regression of renal hyperplasia. Am J Pathol 1989;135:657-62.

24. Liao DJ, Dickson RB. Cell death in MMTV-c-myc transgenic mouse mammary tumors may not be typical apoptosis. Lab Invest 2003;83:1437-49.

25. Galluzzi L, Vitale I, Abrams JM et al. Molecular definitions of cell death subroutines: recommendations of the Nomenclature Committee on Cell Death 2012. Cell Death Differ 2012;19:107-20.

26. Columbano A. Cell death: current difficulties in discriminating apoptosis from necrosis in the context of pathological processes in vivo. J Cell Biochem 1995;58:181-90.

27. Bergmann A, Steller H. Apoptosis, stem cells, and tissue regeneration. Sci Signal 2010;3:re8. doi: 10.1126/scisignal.3145re8.

28. Hochreiter-Hufford A, Ravichandran KS. Clearing the dead: apoptotic cell sensing, recognition, engulfment, and digestion. Cold Spring Harb Perspect Biol 2013;5:a008748. doi: 10.1101/cshperspect.a008748.

29. Gregory CD, Pound JD. Microenvironmental influences of apoptosis in vivo and in vitro. Apoptosis 2010;15:1029-49.

30. Bratton DL, Henson PM. Neutrophil clearance: when the party is over, clean-up begins. Trends Immunol 2011;32:350-7. 
31. Rogers TL, Holen I. Tumour macrophages as potential targets of bisphosphonates. J Transl Med 2011;9:177. doi: 10.1186/1479-5876-9-177.

32. Garabuczi E, Kiss B, Felszeghy S, Tsay GJ, Fesus L, Szondy Z. Retinoids produced by macrophages engulfing apoptotic cells contribute to the appearance of transglutaminase 2 in apoptotic thymocytes. Amino Acids 2013;44:235-44.

33. van Ham TJ, Kokel D, Peterson RT. Apoptotic cells are cleared by directional migration and elmo1- dependent macrophage engulfment. Curr Biol 2012;22:830-6.

34. Tannock IF, Lee C. Evidence against apoptosis as a major mechanism for reproductive cell death following treatment of cell lines with anti-cancer drugs. Br J Cancer 2001;84:100-5.

35. Galluzzi L, Kepp O, Trojel-Hansen C, Kroemer G. Non-apoptotic functions of apoptosis-regulatory proteins. EMBO Rep 2012;13:322-30.

36. Kuranaga E. Beyond apoptosis: caspase regulatory mechanisms and functions in vivo. Genes Cells 2012;17:83-97.

37. Kuranaga E. Caspase signaling in animal development. Dev Growth Differ 2011;53:137-48.

38. Suzanne M, Steller H. Shaping organisms with apoptosis. Cell Death Differ 2013;20:669-75.

39. Miura M. Apoptotic and nonapoptotic caspase functions in animal development. Cold Spring Harb Perspect Biol 2012;4: pii-a008664.. doi: 10.1101/cshperspect.a008664.

40. Wang C, Tai Y, Lisanti MP, Liao DJ. c-Myc induction of programmed cell death may contribute to carcinogenesis: a perspective inspired by several concepts of chemical carcinogenesis. Cancer Biol Ther 2011;11:615-26.

41. Kreuzaler PA, Staniszewska AD, Li W et al. Stat 3 controls lysosomal-mediated cell death in vivo. Nat Cell Biol 2011;13:303-9.

42. Chao MP, Majeti R, Weissman IL. Programmed cell removal: a new obstacle in the road to developing cancer. Nat Rev Cancer 2012;12:58-67.

43. Ekert PG, Vaux DL. The mitochondrial death squad: hardened killers or innocent bystanders? Curr Opin Cell Biol 2005;17:626-30.

44. Vaux DL. Apoptogenic factors released from mitochondria. Biochim Biophys Acta 2011;1813:546-50.

45. Miura M. Active participation of cell death in development and organismal homeostasis. Dev Growth Differ 2011;53:125-36.

46. Liao DJ, Natarajan G, Deming SL et al. Cell cycle basis for the onset and progression of c-Myc-induced, TGFalpha-enhanced mouse mammary gland carcinogenesis. Oncogene 2000;19:1307-17.

47. Shkurupiy VA, Obedinskaya KS, Nadeev AP. Morphological study of the main mechanisms of myometrium involution after repeated pregnancies in mice. Bull Exp Biol Med 2011;150:378-82.

48. Shkurupiy VA, Dubinin EV, Dubinina NN. Structural transformations of myocytes during gestation and early postpartum involution of the uterus. Bull Exp Biol Med 2008;146:845-8.

49. Orfanou DC, Ververidis HN, Pourlis A et al. Post-partum involution of the canine uterus - gross anatomical and histological features. Reprod Domest Anim 2009;44 Suppl 2:152-5.

50. Shukla KK, Mahdi AA, Rajender S. Apoptosis, spermatogenesis and male infertility. Front Biosci (Elite Ed) 2012;4:746-54

51. Shaha C, Tripathi R, Mishra DP. Male germ cell apoptosis: regulation and biology. Philos Trans R Soc Lond B Biol Sci 2010;365:1501-15.

52. Rolaki A, Drakakis P, Millingos S, Loutradis D, Makrigiannakis A. Novel trends in follicular development, atresia and corpus luteum regression: a role for apoptosis. Reprod Biomed Online 2005;11:93-103.

53. Voronina E, Wessel GM. The regulation of oocyte maturation. Curr Top Dev Biol 2003;58:53-110.

54. Guthrie HD, Garrett WM. Apoptosis during folliculogenesis in pigs. Reprod Suppl 2001;58:17-29.

55. Rezzani R, Nardo L, Favero G, Peroni M, Rodella LF. Thymus and aging: morphological, radiological, and functional overview. Age (Dordr ) 2013; epub.

56. Varas A, Sacedon R, Hernandez-Lopez C et al. Age-dependent changes in thymic macrophages and dendritic cells. Microsc Res Tech 2003;62:501-7.

57. Kiess W, Gallaher B. Hormonal control of programmed cell death/apoptosis. Eur J Endocrinol 1998;138:482-91.

58. Reuter VE. Pathological changes in benign and malignant prostatic tissue following androgen deprivation therapy. Urology 1997;49:16-22.

59. Bruchovsky N, Craven S. Prostatic involution: effect on androgen receptors and intracellular androgen transport. Biochem Biophys Res Commun 1975;62:837-43.

60. Godoy A, Montecinos VP, Gray DR et al. Androgen deprivation induces rapid involution and recovery of human prostate vasculature. Am J Physiol Endocrinol Metab 2011;300:E263-E275

61. Castelo-Branco C, Cancelo MJ, Villero J, Nohales F, Julia MD. Management of post-menopausal vaginal atrophy and atrophic vaginitis. Maturitas 2005;52 Suppl 1:S46-S52.

62. Sato T, Fukazawa Y, Kojima H, Ohta Y, Iguchi T. Multiple mechanisms are involved in apoptotic cell death in the mouse uterus and vagina after ovariectomy. Reprod Toxicol 2003;17:289-97. 